\title{
INFLUENCE OF AXIAL SHORTENING OF VERTICAL MEMBER IN THE TALL STRUCTURES
}

\author{
Raksha H L ${ }^{1}$, Karthik $\mathrm{S}^{\mathbf{2}}$, Madhukeshwara $\mathrm{J}^{3}$ \\ ${ }^{1}$ M.Tech, Department of Civil Engineering, Global Academy of Technology, Bengaluru-560098 \\ ${ }^{2}$ Assistant Professor, Department of Civil Engineering, Global Academy of Technology, Bengaluru-560098 \\ ${ }^{3}$ Structural Engineer, Arcis Consultants, Bengaluru
}

\begin{abstract}
Nowadays, there is major demand for commercial and the residential buildings due to population growth in our country, this results in construction of large no of tall structures. Reinforced concrete is the most common material used for the construction of the tall buildings. During the analysis the gravity load, lateral loads due to earthquake, other loads and their load combinations should be considered. Nowadays to avoid the lateral displacement large column sizes are provided which is not economical. Therefore, the core with shear wall are provided. These shear walls will not only resist the lateral loads due to earthquake but it also resist the axial loads acting on the tall structure. This may lead to shortening between two neighboring vertical member. The conventional method is the method of analysis considered for tall buildings. In this method all loads applied in a single step ie post construction stage analysis, but in practice self-weight and part of live load are released on the building gradually as the construction progresses and therefore construction stage analysis using E-TABS software dynamic analysis ie Response spectrum needs to be carried out. In the present work, a parametric study is carried out on Axial shortening of vertical members in tall structure. The parameters considered are varying the columns sizes, increasing storey height and grade of concrete. Comparison of various parameters such as differential shortening using post construction stage analysis and construction stage analysis is studied.
\end{abstract}

Keywords: Core Wall, Axial Shortening, Construction Analysis, Post Construction Stage Analysis, E-TABS

\section{INTRODUCTION}

The concrete is significant material which is used for construction of the tall structures. The main components like beams and columns that helps in load bearing in the concrete structure is subjected to long term shortening which is time dependent causing the effect like 'creep' and 'shrinkage'.

The shortening of load bearing components like beams and columns in the tall structures was prepared by the combinations of materials like concrete and steel in the tall structures. The effect of creep and shrinkage will not have significant effect on the building whose height is lesser than 30 storey. The effect will only be seen in the building whose height is higher than 30 storey like it may be 40,50 and 60 storey and so on. Storey with the height ranging 40 to 60 storey showed the significant impact of creep and shrinkage in the high rise building.

The controlling of the shortening of column is very difficult for the building whose height is higher than 400 meters and above. The reinforced concrete is used and concrete with steel enclosed are used as construction material of tall buildings. The steel which is used helps in resisting the loads which are acting on structure. They also increase the concrete performance in the structure. The main members which are affected by axial shortening are beams ,columns, shear walls they undergo compression. This also leads to differential axial shortening in the tall buildings.

\subsection{Axial Shortening of Columns}

RC columns, walls ,beams shortens leading to elastic compression, and also to creep effect and shrinkage effect, Even though it is not effective for the buildings less than about 10 to 20 stories. It also leads to movement of beams and columns, causing restraints and cracking in concrete buildings. Columns, beams and walls in tall buildings shorten by various amounts and at various times. The Axial shortening is caused because of increase in height or the increase in no of storey and also the complex nature of the structure.

The maximum shortening of the column is seen at the roof, reduces to zero at the bottom. No process or a very less phenomena can be done to lessen the physical process of shortening, The designer of the building should be cautious of the problem that occur at the building, joints can be provided, if necessary, in between the framing system and cladding to avoid axial load being transferring into the building.

The loads which acts axially from all columns in the structure are hardly same, they leads to problem which is nothing but differential shortening. This problem is more severe in the complex structure because steel is erected in the columns that are later which are enclosed in the concrete are slender, therefore they lead to the large axial loads during the time of construction. The magnitude of axial shortening in a complex structure is difficult to determine 
and complicated because many of the things that leads to the shortening is very difficult to predict it with accuracy. Example, the bottom of the composite column undergoes creep effect. The steel that is erected in the column at the time of construction which is enclosed in the concrete at bottom floors, The column steel which is projecting at the several floor at the concreted level.

The important factor that is difficult to find is the gravity loading that redistributes because of action of frame of the columns. The settlement in foundation is also the another factor that leads to the change in the elevations in columns. This leads to load imbalance in between two columns is continuously changing, leading to the shortening of column. The differential shortening of columns is more significant rather than absolute shortening.

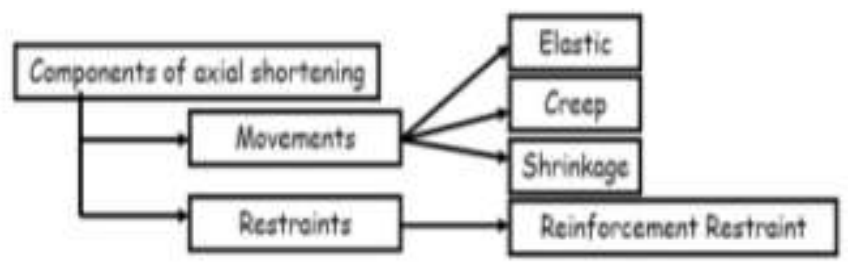

Fig-1 Main Components of axial shortening

\subsection{Need for Present Study}

The study of influence of axial shortening of the vertical member in the tall building by varying the height of the building. Most of the studies are confined to a particular loads, where in reality a structure needs to be analyzed for all the loads and for all possible load combinations to arrive at a critical load combination and such studies are limited. The following results are compared.

Differential shortening.

Axial load acting on the column .

Differential shortening of column

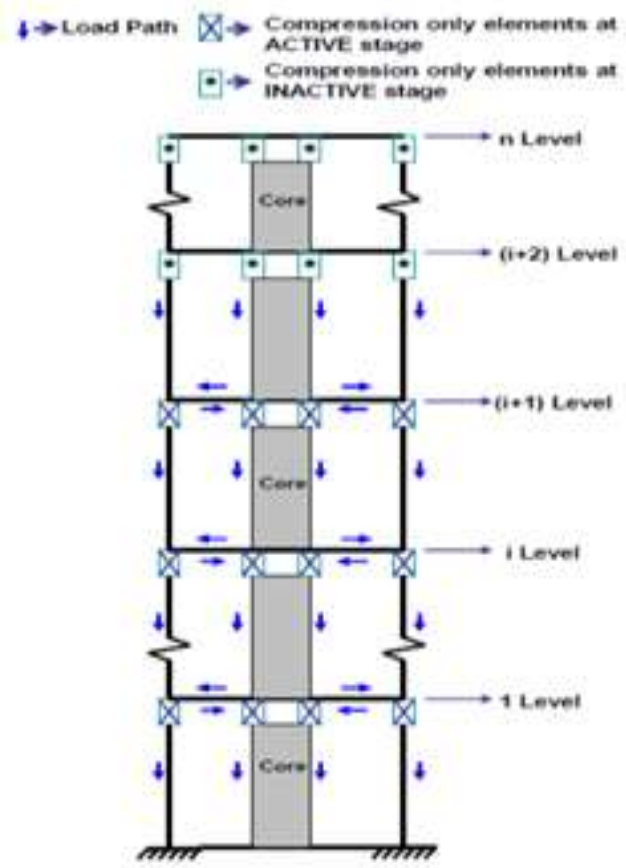

Fig-2 Load transfer mechanism in the building

\subsection{Objective of the Study}

The main aim or the objective of the thesis is to develop an understanding of the behavior of axial shortening of the column due to the effect of creep, shrinkage, and also the temperature effect under the seismic condition .

The objectives of the study are:

- To study the behavior of the columns and the core wall due to the action of creep and shrinkage effect during the construction stage and also after the construction stage.

- To analyze the seismic performance of the vertical members of the concrete structure which occurs in their service life.

- To find the effect of seismic action on the vertical member under construction stage and also after the construction stage.

- To verify the behavior of the vertical member i,e columns and core walls by Dynamic analysis (Response spectrum) method using the commercial software E-tabs 15.2.2.

- To check the behavior of the building under the application of the load.

- To analyze the seismic performance of the building and also analysis of the axial shortening of the vertical member during the construction stage of the tall building and also without taking the construction stage into consideration.

\section{BUILDING DESCRIPTION}

In this study 6 types of models are chosen. The plan, height of floor, deck slab thickness, floor finish load, wall load , and live load remains the same for all the models. There are 6 models with the same plan which consists of $\mathrm{G}+19$ stories, $\mathrm{G}+39$ stories, and also $\mathrm{G}+59$ stories the 6 models are prepared using the same grade of concrete and steel in which 3 models are prepared for the construction stage analysis and also other 3 models are prepared for post construction stage. Analysis is carried out by considering a fixed support at the base of the building, using reference plan. The grade of concrete is considered in the present analysis i,e M30 grade , M40grade and also M60grade is used and the building height is varied for 20 storey, 40 storey and also 60 storey is used in the present analysis.

\subsection{Loading Details}

Table-1 Loading Details

\begin{tabular}{|l|l|l|}
\hline SL .NO & $\begin{array}{l}\text { TYPE OF } \\
\text { LOADING }\end{array}$ & LOAD \\
\hline 1 & Live load & $4 \mathrm{kN} / \mathrm{m}^{\wedge} 2$ \\
\hline 2 & Super dead load & \\
\hline a) & Floor Finish load & $2 \mathrm{kN} / \mathrm{m}^{\wedge} 2$ \\
\hline b) & Glazing load & $10 \mathrm{kN} / \mathrm{m}$ \\
\hline
\end{tabular}


- The architectural plan of the building is shown as below or the reference plan of the building

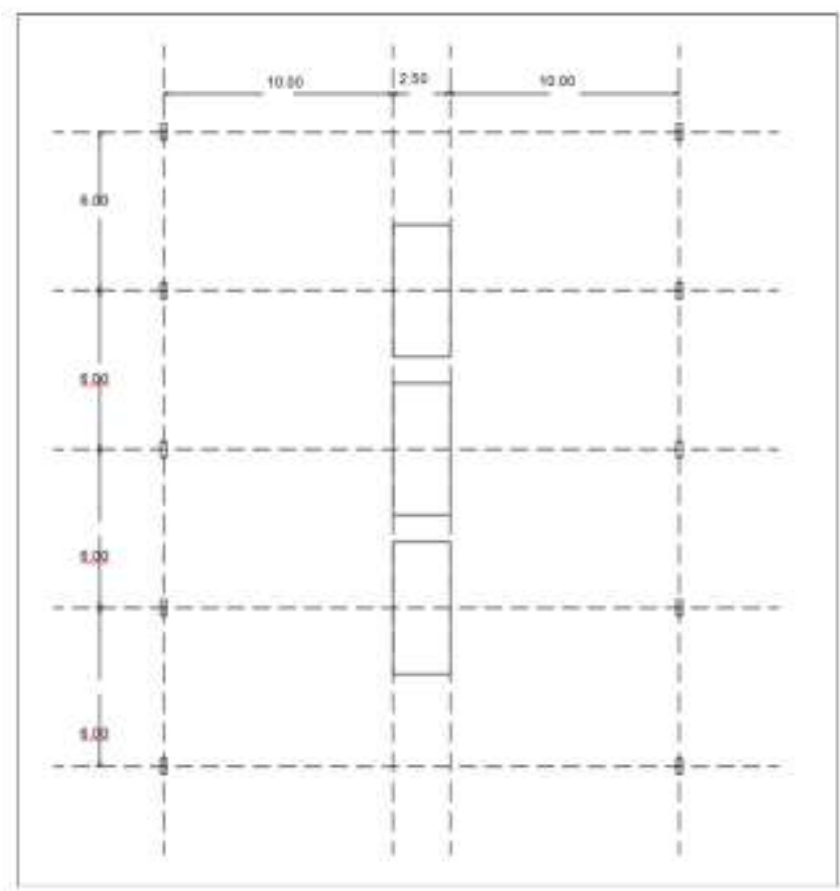

2.2 Modeling and Analysis of the Building Using Etabs

- Setting Up the Storey Data

Table-2 Setting Up The Storey Data

\begin{tabular}{|l|l|l|}
\hline SL. NO & DATA & DIMENSION \\
\hline 1 & No of storey & $\mathrm{G}+19$ \\
\hline 2 & Storey height & $3 \mathrm{~m}$ \\
\hline 3 & Total storey height & $60 \mathrm{~m}$ \\
\hline
\end{tabular}

- Defining Material Properties

Table-3 Defining material properties

\begin{tabular}{|l|l|l|}
\hline SL.NO & $\begin{array}{l}\text { MATERIAL } \\
\text { PROPERTIES }\end{array}$ & GRADE \\
\hline 1 & $\begin{array}{l}\text { Compressive strength of } \\
\text { concrete }\end{array}$ & M 30,M40,M60 \\
\hline 2 & $\begin{array}{l}\text { Characteristic strength of } \\
\text { reinforcement }\end{array}$ & Fe 500 \\
\hline
\end{tabular}

- Defining Frame And Slab Properties

Table-3 Defining Frame and Slab Properties

\begin{tabular}{|l|l|l|}
\hline SL NO & TYPE & SIZE \\
\hline 1. & COLUMN & $0.8 * 0.8$ \\
\hline 2. & BEAM & $0.5 * 0.9$ \\
\hline 3. & SLAB & 0.2 \\
\hline 4. & CORE WALL & 0.5 \\
\hline
\end{tabular}

\subsection{Assigning the Properties of the Member}

- Assigning the properties of the column

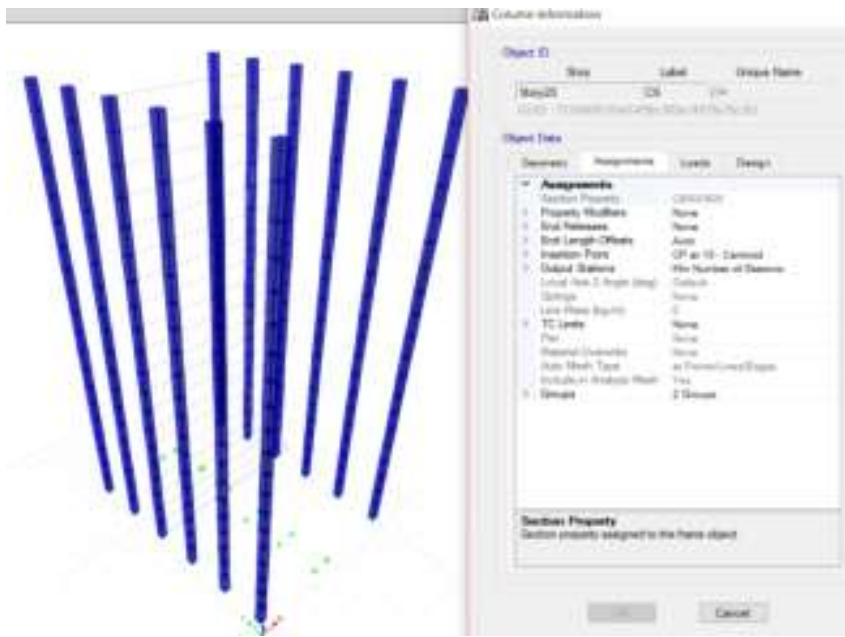

Fig-3 Assigning the properties of the column

- Assigning the property of the beams as mentioned in the table for whole structure

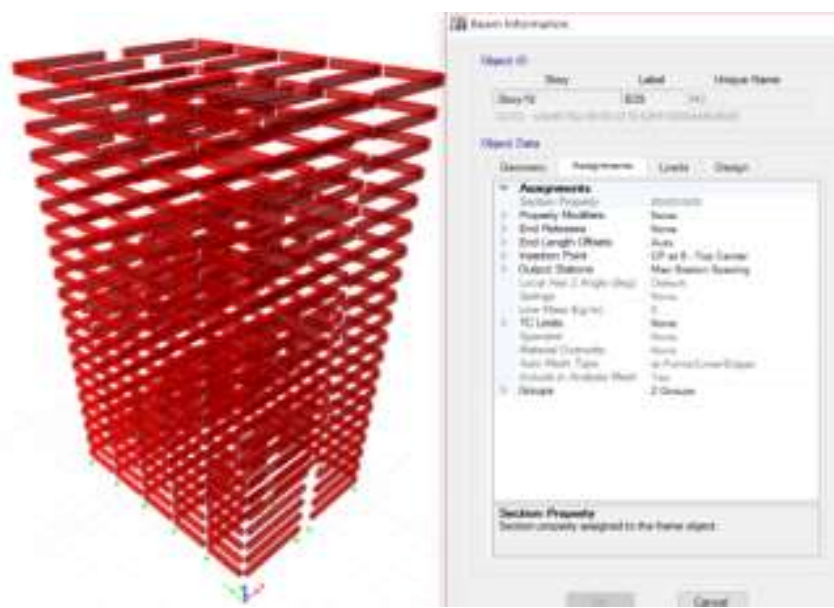

Fig-4 Assigning the properties of the beam

- Assigning the property of the slab as mentioned in the table for whole structure

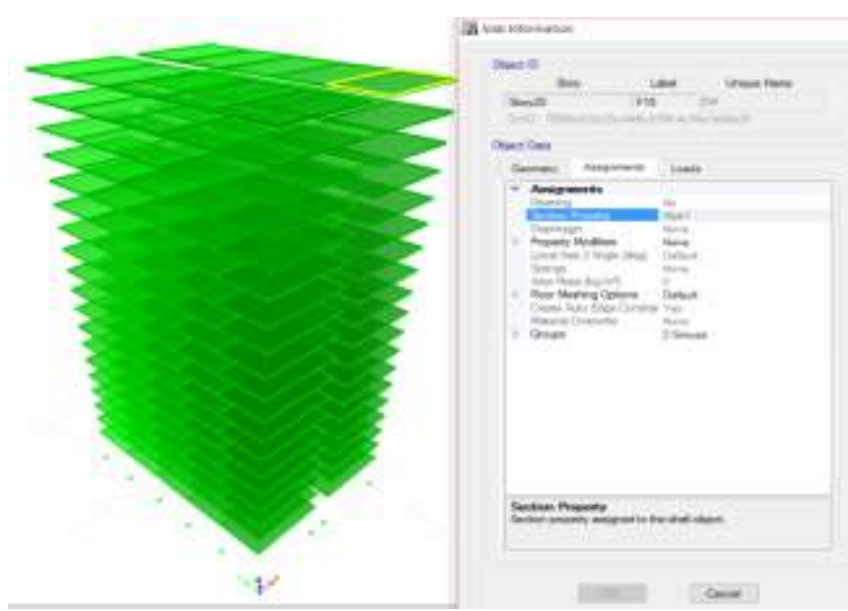

Fig-5 Assigning the properties of the slab 
- Assigning the property of the core wall according to the storey height as mentioned in the table for whole structure

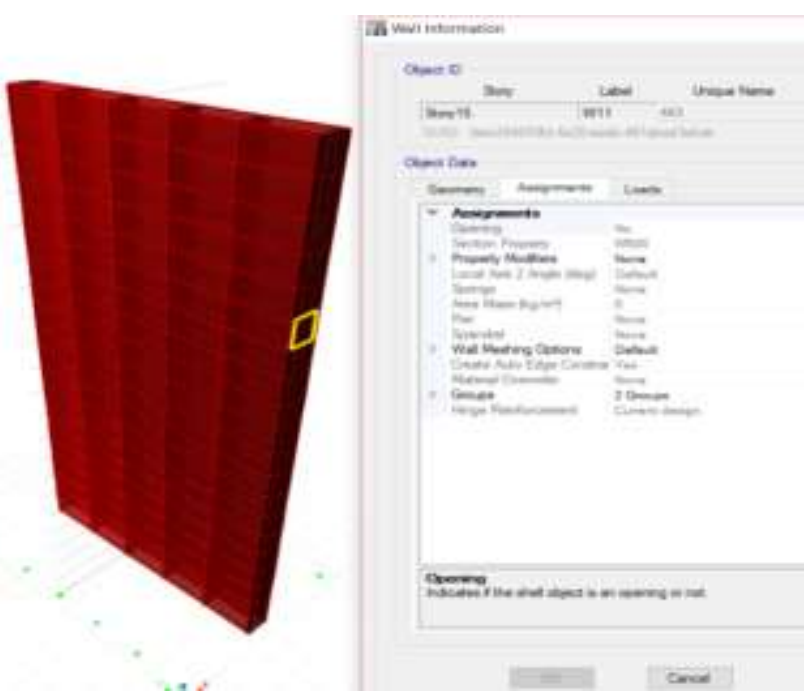

Fig-6 Assigning the properties of the core wall

- 3D View of the building

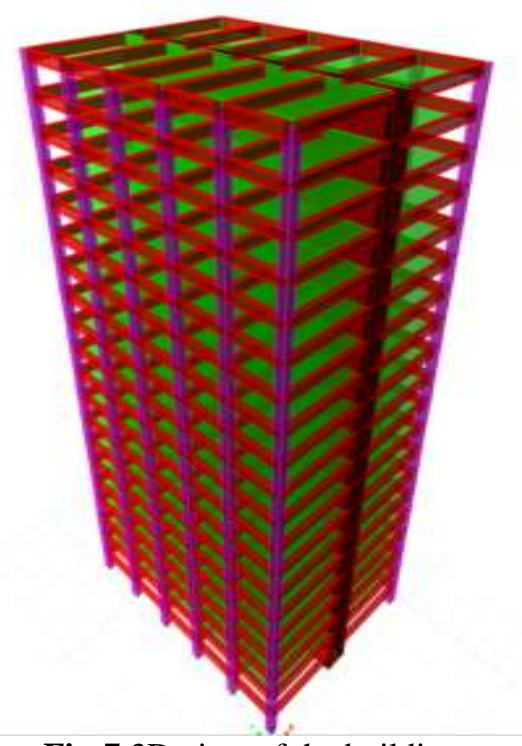

Fig-7 3D view of the building

\section{RESULTS AND DISCUSSIONS}

\subsection{Differential Displacement}

The results for typical floor differential displacement between the column and the core wall in the 20,40,60 storey structure are taken into consideration for both construction stage(CS) and post construction stage(PCS) and tabulated.

The value of the displacement is taken for the interval of 5 story in the column and core wall and tabulated .The typical example is show below.
3.2 Displacement Values For 20storey M30 grade Cs And Pes Analysis

Table-3 Displacement Values For 20storey M30 grade Cs And Pcs Analysis

\begin{tabular}{|l|l|l|l|l|}
\hline & \multicolumn{2}{|l}{ COLUMN } & \multicolumn{2}{l|}{ CORE WALL } \\
\hline Storey & CS & PCS & CS & PCS \\
\hline 5 & 3.562 & 3.76 & 1.197 & 1.357 \\
\hline 10 & 4.759 & 6.411 & 1.675 & 2.362 \\
\hline 15 & 3.455 & 7.997 & 1.381 & 2.574 \\
\hline 20 & 0.842 & 8.576 & 0.305 & 2.75 \\
\hline
\end{tabular}

\section{Storey M30 Grade}

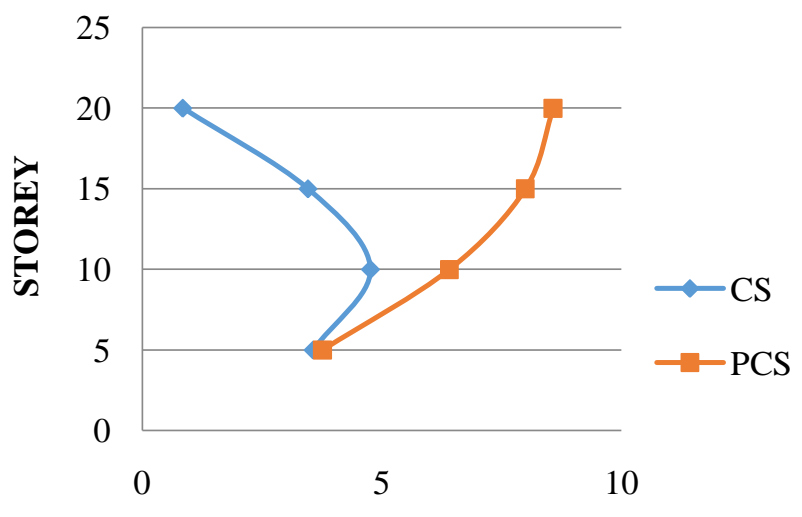

DIFFRENTIAL DISPLACEMENT IN COLUMN

Chart-1 Displacement In Column For 20SM30

\section{Storey M30 Grade}

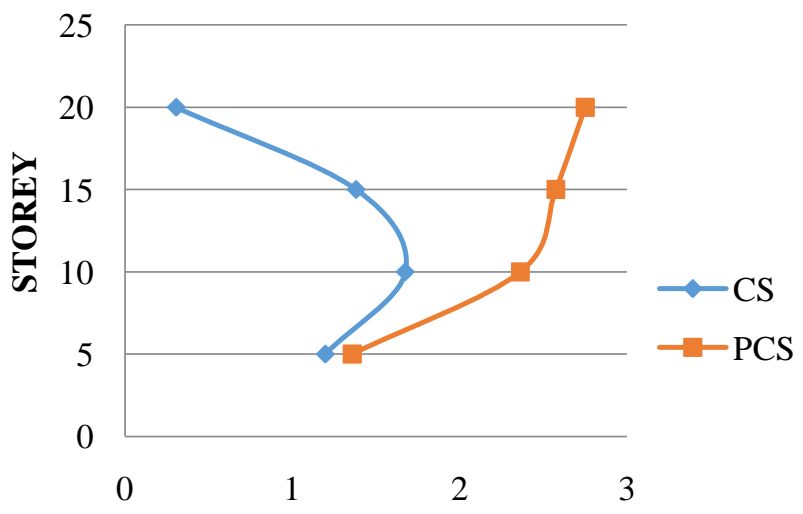

DIFFRENTIAL DISPLACEMENT IN CORE WALL

Chart-2 Displacement In Core wall For 20SM30 


\section{Storey M30 Grade}

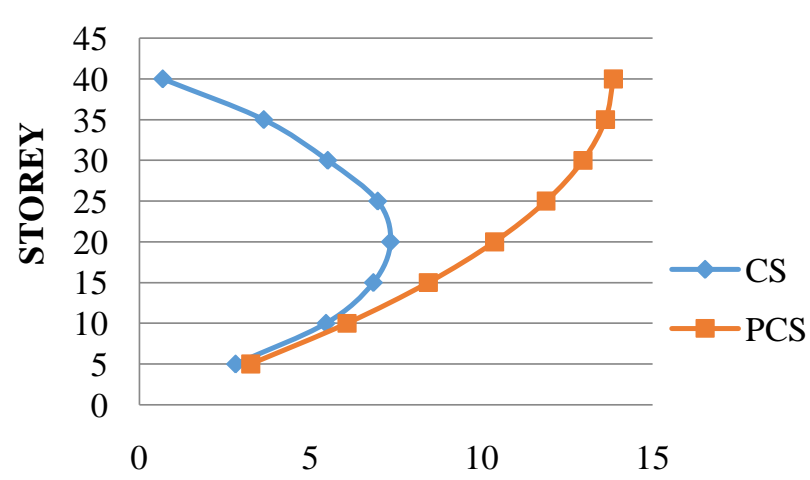

\section{DIFFRENTIAL DISPLACEMENT IN COLUMN}

Chart-3 Displacement In Column For 40SM30

\section{Storey M30 Grade}

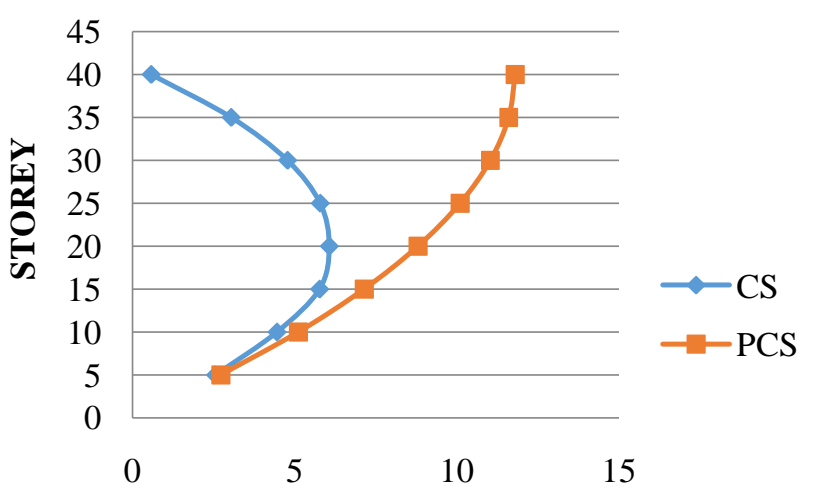

\section{DIFFRENTIAL DISPLACEMENT IN CORE WALL}

Chart-4 Displacement In Core wall For 40SM30

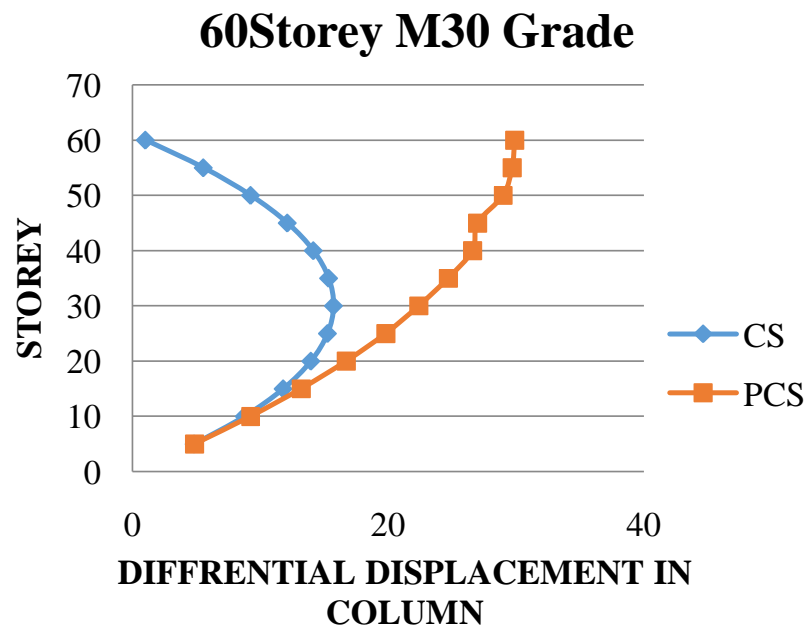

Chart-5 Displacement In Column For 60SM30

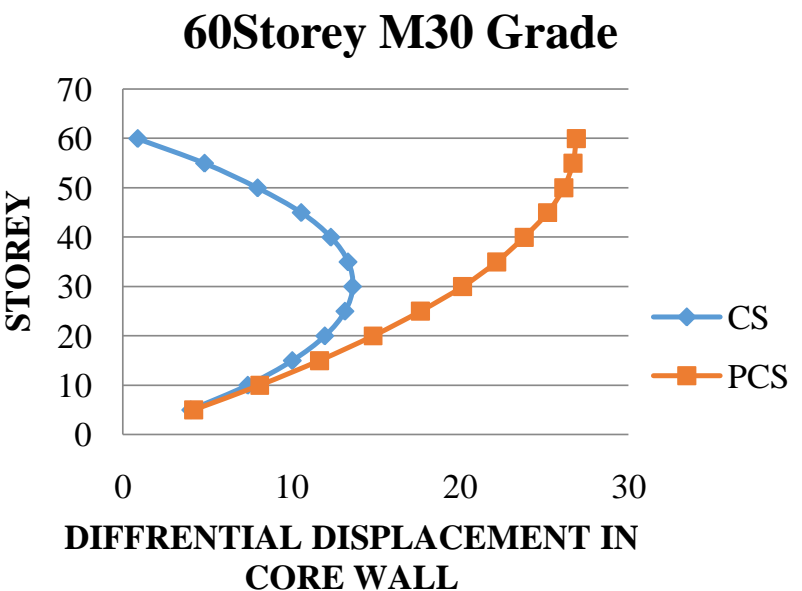

Chart-6 Displacement In Core wall For 60SM30

The results of both construction stage and post construction stage of typical floor diffrential displacement is tabulated for column and core wall. The results that are obtained in construction stage and post construction stage are plotted in the graph for comparision.The graph of 20,40,60 storey with different grade of concrete i,e M30,M40,M60 is studied. In the above graph change in grade of concrete there is a significant change in the displacement for 20, 40, 60 storey. The maximum floor displacement in 20 storey is 3.562 in CS ,8.576 in PCS for M30 in column, 1.197 in CS and 3.19 in PCS for M30 core wall. For 20storey M40 is 3.112 in CS, 7.540 in PCS for M40 in column,1.191 in CS and 3.166 in PCS for M40 in core wall. . For 20storey M60 is 3.11 in CS, 7.54 in PCS for M60 in column,1.191 in CS and 3.166 in PCS for M60 in core wall.

The maximum floor displacement in 40 storey is $7.341 \mathrm{~mm}$ in CS ,13.851mm in PCS for M30 in column, $6.066 \mathrm{~mm}$ in CS and 11.803 in PCS for M30 core wall. For 40storey M40 is 7.318 in CS, 13.893 in PCS for M40 in column,6.091 in CS and11.855 in PCS for M40 in core wall. . For 40storey M60 is 6.21 in CS, 11.85 in PCS for M60 in column,5.92 in CS and 11.46 in PCS for M60 in core wall.

The maximum floor displacement in 60 storey is 15.73 in CS ,29.9 in PCS for M30 in column, 13.64 in CS and 26.9 in PCS for M30 core wall. For 60storey M40 is 14.047 in CS, 27.01 in PCS for M40 in column,13.25 in CS and 25.92 in PCS for M40 in core wall. . For 60storey M60 is 11.997 in CS, 23.0 in PCS for M60 in column,12.68 in CS and 24.41 in PCS for M60 in core wall.

In this present analysis it clearly indicates that as the storey height increases the differential displacement also increases both in column and core wall during construction stage and post construction stage due to the effect of creep and shrinkage in different grade of concrete. 


\subsection{Differential Shortening}

The construction stage and post construction stage analysis results to differential shortening of the column in 20,40 and 60 storey buildings. The differential shortening is calculated by taking difference between the deformation value of the column and the core wall of particular storey.The typical example of 20 storey is tabulated and the graph is plotted accordingly.

Table-4 Differential Shortening Value For 20SM30

\begin{tabular}{|l|l|l|}
\hline STOREY & CS & PCS \\
\hline 5 & 2.365 & 2.403 \\
\hline 10 & 3.084 & 4.049 \\
\hline 15 & 2.074 & 5.423 \\
\hline 20 & 0.537 & 5.386 \\
\hline
\end{tabular}

\section{Storey M30 Grade}

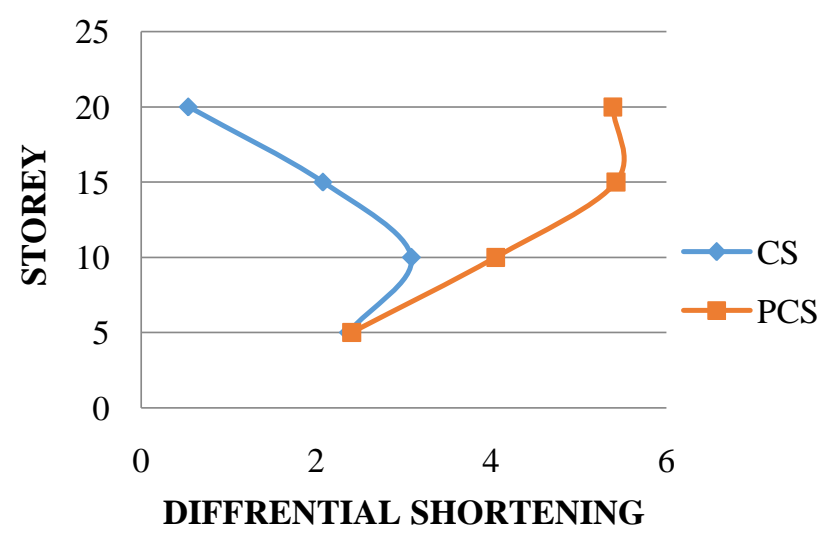

Chart-7 Differential shortening In 20SM30

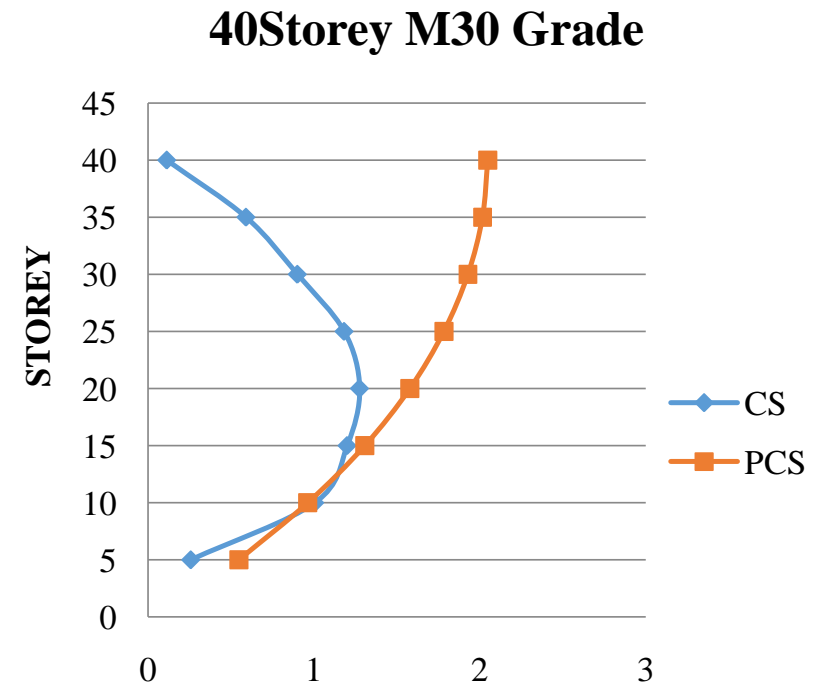

DIFFRENTIAL SHORTENING

Chart-8 Differential shortening In 40SM30

\section{Storey M30 Grade}

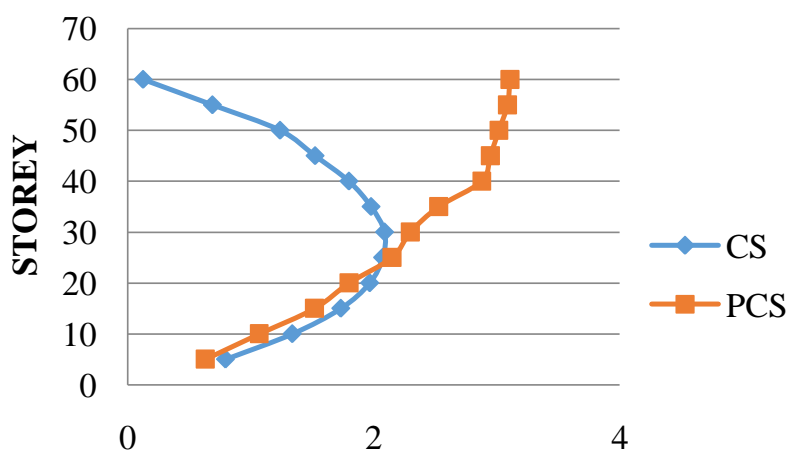

DIFFRENTIAL SHORTENING

Chart-9 Differential shortening In 60SM30

The results of differential shortening in construction stage and post construction stage in 20,40, 60 storey is plotted in the above graph for different grade of concrete i,e M30, M40,M60 .The comparision is done for 20,40, 60 storey height and for different grade of concrete.

The graph of storey v/s diffrential shortening is plotted for 3 different grade of concrete and storey height and is studied in the present work. The diffrential shortening of the vertical memeber are estimated both in construction stage and post construction stage.

In 20-storey the maximum differential shortening is $5.386 \mathrm{~mm}$ in CS and in PCS $3.084 \mathrm{~mm}$ was observed for 20M30,for 20M40 is $6.193 \mathrm{~mm}$ in CS and in PCS $2.534 \mathrm{~mm}$ was observed, for $20 \mathrm{M} 60$ is $3.173 \mathrm{~mm}$ in CS and in PCS $1.833 \mathrm{~mm}$ was observed.

In 40-storey the maximum differential shortening is $1.275 \mathrm{~mm}$ in CS and in PCS $2.048 \mathrm{~mm}$ was observed for 40M30,for 40M40 is $1.069 \mathrm{~mm}$ in CS and in PCS $2.038 \mathrm{~mm}$ was observed, for $40 \mathrm{M} 60$ is $0.29 \mathrm{~mm}$ in CS and in PCS 0.41 mm was observed.

In 60-storey the maximum differential shortening is 2.09 $\mathrm{mm}$ in CS and in PCS $3.0 \mathrm{~mm}$ was observed for 60M30,for $60 \mathrm{M} 40$ is $1.059 \mathrm{~mm}$ in CS and in PCS $1.09 \mathrm{~mm}$ was observed, for $60 \mathrm{M} 60$ is $0.688 \mathrm{~mm}$ in CS and in PCS 1.01 mm was observed.

In this present work by comparing differential shortening in both construction stage and post construction stage as the storey height increases the value of differential shortening also increases due to long term effect of creep and shrinkage and also it is observed that as the grade of the concrete increases the differential shortening decreases.

As a result as the storey height increases the differential shortening also increases and also we can tell that as the grade of concrete ie M30, M40, M60 increases the shortening of the vertical member decreases. 


\subsection{Column Axial Force}

The vertical deformation in the column are more than that of the core wall, limited column axial forces are released in the horizontal beams to the core wall however, in the analysis of all cases shows that axial force distribution between column and shear wall is not significantly affected by variation in floor levels.

Table-5 Column axial force Value For 20SM30

\begin{tabular}{|l|l|l|}
\hline STOREY & CS IN kN & PCS IN kN \\
\hline 5 & 4196 & 3898 \\
\hline 10 & 2907 & 2606 \\
\hline 15 & 1628 & 1399 \\
\hline 20 & 281.6 & 236.9 \\
\hline
\end{tabular}

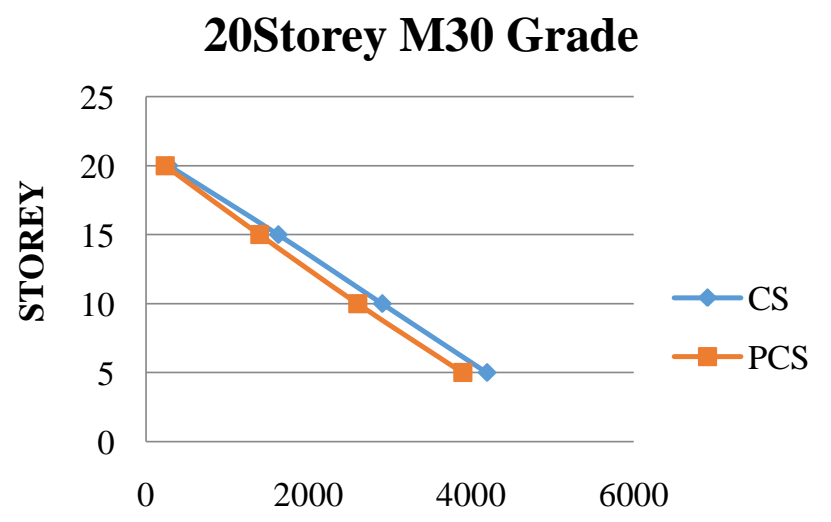

COLUMN AXIAL FORCE

Chart-10 Differential shortening In 20SM30

40Storey M30 Grade

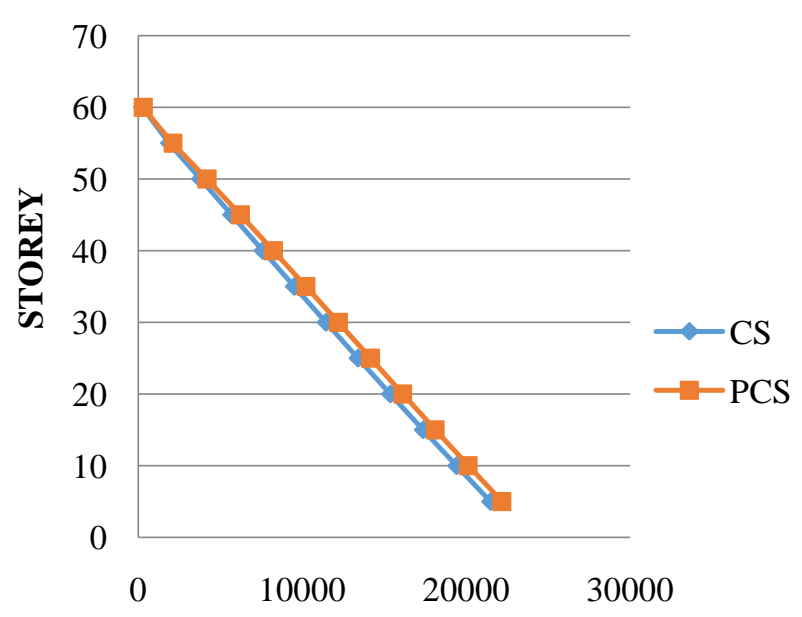

COLUMN AXIAL FORCE

Chart-11 Differential shortening In 40SM30

\section{Storey M30 Grade}

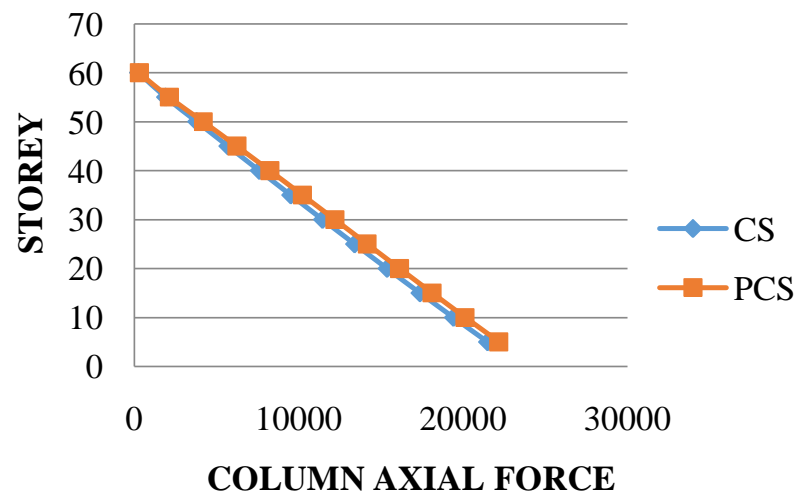

Chart-12 Differential shortening In 60SM30

The vertical deformation in the column are more than that of the core wall, the partial of the column axial forces are released to the beams then to the core walls The graph of column axial force $\mathrm{v} / \mathrm{s}$ storey height is plotted, and comparison is carried out for different storey height i,e 20, 40, 60 storey and different grade of concrete i,e M30, M40, and M60.

In 20-storey the maximum column axial force is $4196 \mathrm{kN}$ in CS and in PCS $3898 \mathrm{kN}$ was observed for 20M30, for $20 \mathrm{M} 40$ is $3966.6 \mathrm{kN}$ in CS and in PCS $3685 \mathrm{kN}$ was observed, for 20M60 is $4017 \mathrm{kN}$ in CS and in PCS $3769 \mathrm{kN}$ was observed.

In 40-storey the maximum column axial force is $14480 \mathrm{kN}$ in CS and in PCS $14085.6 \mathrm{kN}$ was observed for 40M30, for $40 \mathrm{M} 40$ is $12912 \mathrm{kN}$ in $\mathrm{CS}$ and in PCS $12493.5 \mathrm{kN}$ was observed, for $40 \mathrm{M} 60$ is $12886 \mathrm{kN}$ in $\mathrm{CS}$ and in PCS $13225 \mathrm{kN}$ was observed.

In 60 -storey the maximum column axial force is $21482.3 \mathrm{kN}$ in CS and in PCS $22182.6 \mathrm{kN}$ was observed for 60M30, for $60 \mathrm{M} 40$ is $22705.9 \mathrm{kN}$ in CS and in PCS $22269.9 \mathrm{kN}$ was observed, for $60 \mathrm{M} 60$ is $23505.6 \mathrm{kN}$ in $\mathrm{CS}$ and in PCS $23452.0 \mathrm{kN}$ was observed.

\section{CONCLUSION}

$>$ The comparison of models with construction stage and post construction stage is carried out the value of differential shortening of vertical member in construction stage made large difference compared to post construction stage analysis. It is because of self weight and portion of live load which is applied sequentially in construction stage analysis during the actual construction. This shows that the construction stage value is very realistic.

$>$ We can say that as the height of the structure increases the shortening of the column also become more significant in the buildings.

$>$ In order to get the proper effect of differential shortening in column it is recommended to use construction stage analysis for concrete, because the post construction stage analysis for the whole building 
always erroneously estimate the behaviour of the column.

$>$ The shortening of column is mainly due to time dependent effect i,e, creep and shrinkage effect the major shortening occur during the construction stage.

$>$ The shortening effect in the column is very important in short as well as in the tall structures if the construction rate is more . it is not more significant to short buildings whose construction rates are less compared to tall buildings .

$>$ As the grade of the concrete used in the structure increases the values of the shortening decreases. This effect is due to increase in Modulus of elasticity.

$>$ As the height of structure increases above 20 storey, the effect of differential shortening should not be disregarded.

$>$ The effect of differential shortening in a building is maximum at the mid height of the structure .

$>$ To get the accurate value of the analysis of the building the construction stage analysis should be carried out.

$>$ As the size of the column increases the shortening in the column also decreases.

\section{REFERENCES}

[1]. M.HassanienSerror and A.Essam El-Din, “ assessment of internal forces induced due to differential shortening of vertical elements in typical medium to high-rise buildings", journal of American science,vol.8, no.12,pp 161174,2012,ISSN:1545-1003.

[2]. SnehalD.Poojara and Dr.PareshV.Patel, "axial deformation of columns in multi-story R.C buildings", IJCIET. Vol.5, no.3, pp 294-300, march 2014, ISSN:09766308.

[3]. Tianyi Yi and Xiangdong Tong, "Differential Column Shortening Effect In Typical Medium To High Rise Buildings", Structures Congress: New Horizons And Better Practices, ASCE, pp 1-10, 2007

[4]. Han-Soo Kim And Suk-Hee Cho, "Column Shortening of Concrete Cores and Composite Columns In a Tall Building”, CTBUH, Vol.14, No.2, pp175-190, June2005.

[5]. Fintel $\mathrm{M}$, Ghosh SK and Tyengar H, "Column Shortening In Tall Structures-Prediction And Compensation", Portland Cement Association In Skokie, 1987, pp 1-33.

[6]. Smith BS and Loull A, "Tall Building Structures Analysis And Design", John Wiley And Son, Inc, 1991, pp461-479.

[7]. AM Neville, "Properties Of Concrete", Fourth Edition, Longman, Harlow, Essex, England.

[8]. Bungale S Taranath, "Reinforced Concrete Design of Tall Buildings", Taylor\& Francis Group, 2010, ISBN 978-14398-0480-3.

[9]. M.T.R.Jayasinghe and W.M.V.P.K.Jayasena, "Effects Of Axial Shortening Of Column On Design And Construction Of Tall Reinforced Concrete Buildings", Practice Periodical On Structural Design And Construction, ASCE, Vo.9, No.2, pp 70-78, May 2004, ISSN:1084-0680

\section{BIOGRAPHIES}

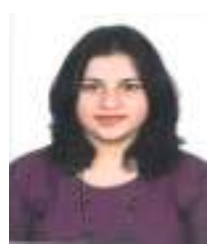

Raksha H L, M.Tech Student, Department of Civil Engineering, Global Academy of Technology, Bengaluru -560098

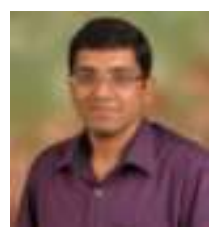

Karthik S, Asst. Professor, Department of Civil Engineering, Global Academy of Technology, Bengaluru -560098

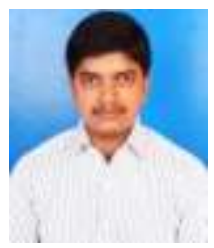

Madhukeshwara J E, Structural Engineer, Arcis consultants, Bengaluru 